\title{
Liver transplantation: survival and indexes of donor-recipient matching
}

\author{
Fábio Silveira1* (1), Fabio Porto Silveira' (D), Alexandre Coutinho Teixeira de Freitas ${ }^{2,3}(\mathbb{D}$, \\ Júlio Cezar Uili Coelho 2,3 (B), Eduardo José Brommelstroet Ramos ${ }^{3}$ (i), \\ Matheus Martin Macri ${ }^{4}$ (D) Nertan Tefilli ${ }^{5}$, L Luis Cesar Bredt ${ }^{6}$
}

\section{SUMMARY}

OBJECTIVE: The aim of this study was to determine the prospective capacity and impact of donor risk index, preallocation survival outcomes following liver transplant, donor model for end-stage liver disease, and balance of risk on patients' 30-day survival after liver transplantation.

METHODS: We prospectively analyzed patient survival in a multicentric observational cohort of adult liver transplantation through the year of 2019 at the state of Paraná, Brazil. The receiver operating characteristic curve, the area under the curve, and the best cutoff point (i.e., the Youden's index) were estimated to analyze the prognostic value of each index.

RESULTS: In total, 252 liver transplants were included with an average model for end-stage liver disease score of 21.17 and a 30 -day survival of $79.76 \%$. The donor risk index was the only prognostic variable with no relation to patients' 30 -day mortality model for end-stage liver disease and donor model for end-stage liver disease have no prognostic value on receiver operating characteristic curve, but preallocation survival outcomes following liver transplant, survival outcomes following liver transplant, and balance of risk presented good relationship with this observation. The cutoff value was estimated in 11-12 points for balance of risk and 9-12 for preallocation survival outcomes following liver transplant and survival outcomes following liver transplant. The 30-day survival for the group of transplants with scores up to 12 points $(n=172)$ in all the three indexes was $87.79 \%$, and for those transplants with scores higher than 12 it was $36.36 \%$.

CONCLUSIONS: The 30 -day survival is $79.76 \%$, and balance of risk, survival outcomes following liver transplant, and preallocation survival outcomes following liver transplant are the good prognostic indexes. The cutoff value of 12 points has clinical usefulness to predict the post-liver transplantation results.

KEYWORDS: Liver transplantation. Risk assessment. Survival analysis.

${ }^{1}$ Hospital do Rocio, Serviço de Transplante Hepático - Campo Largo (PR), Brazil.

Universidade Federal do Paraná, Hospital de Clínicas, Serviço de Transplante Hepático - Curitiba (PR), Brazil.

${ }^{3}$ Hospital Nossa Senhora das Graças, Serviço de Transplante Hepático - Curitiba (PR), Brazil.

${ }^{4}$ Hospital Angelina Caron, Serviço de Transplante Hepático - Campina Grande do Sul (PR), Brazil.

${ }^{5}$ Hospital São Vicente, Serviço de Transplante Hepático - Curitiba (PR), Brazil.

${ }^{6}$ União Oeste Paranaense de Estudos e Combate ao Câncer, Serviço de Transplante Hepático - Cascavel (PR), Brazil.

*Corresponding author: silveira.fabio@gmail.com

Conflicts of interest: the authors declare there are no conflicts of interest. Funding: none.

Received on March 12, 2021. Accepted on March 13, 2021. 


\section{INTRODUCTION}

Since liver transplantation was already well established as the most appropriate treatment for end-stage liver diseases, it involves a myriad of factors related to the donor, recipient, anesthetic-surgical procedure, and intensive care management which influence the occurrence of complications, survival, and costs ${ }^{1,2}$.

Many indexes have been validated to analyze survival, e.g., donor risk index $(\mathrm{DRI})^{3}$, balance of risk (BAR $)^{4}$, survival outcomes following liver transplant (PSOFT/SOFT) ${ }^{5}$, and donor model for end-stage liver disease (DMELD) ${ }^{6}$.

Recently, Parana’s State Transplant System has outgained national prominence for the increase in the number of brain death notifications, effective donors, and number of transplants, reaching the mark of 43.8 effective donors per million of population in $2019^{7}$. Thus, the State Transplant Agency is concerned not only with transplantation number, but also with receptor's survival ${ }^{8}$. No other prospective and multicentric study was published in Brazil evaluating state results.

To analyze this issue, it demanded a joint action evolving all hospitals registered for liver transplantation at the state and coordinated by the State Transplant Agency ${ }^{9}$. Each hospital had one representative composing the state technical board who was responsible to prospectively collect the data. This study aims to:

(A) determine patients' 30-day survival after liver transplantation during the year of 2019;

(B) examine the capacity of MELD, DMELD, DRI, PSOFT, SOFT, and BAR as the survival prognostic indexes in our local reality; and

(C) evaluate the impact of the selected prognostic indexes on patient survival.

\section{METHODS}

This is a prospectively collected multicentric observational cohort of all liver transplantation donors and recipients through the year 2019 at the state of Paraná, Brazil. The inclusion criteria were adult recipients ( $>12$ years of age) who received deceased donor organs. The exclusion criteria were living donor organs, impossibility to finish the organ implant surgery, and multiple organ transplantation.

We analyzed patients' 30 -day cumulative survival and the survival according to the following risk indexes calculated from the information collected from the donors and recipients as previously published: MELD, DMELD, DRI, PSOFT, SOFT, and BAR.

A logistic regression analysis to model the probability of the dichotomic event (dead/not dead) in a linear combination of one or more independent variables was used to study the associated factors. Quantitative variables were assessed by the analysis of variance (ANOVA) for parametric data and the Kruskal-Wallis test for nonparametric data.
Aiming to investigate the best observed representation of prognostic scores, which could be more appropriate in allocation decisions for our cohort, a receiver operating characteristic (ROC) curve with the calculation of the area under the curve (AUROC) was performed to all the indexes. The best cutoff point was estimated by calculating the highest Youden's index.

The level of significance adopted in all the analyses was $5 \%$. The data collection and analysis were performed using EpiInfo $^{\mathrm{TM}}$ Epidemiological software (version 7.2.2.16, Center for Disease Control and Prevention) ${ }^{10}$.

As this study used only the aggregated data that are entirely anonymous, the approval of the Research Ethics Committee (CEP) was not necessary, according to the Resolution No. 510/2016 of the National Health Council (CNS) in Brazil.

\section{RESULTS}

The group under analysis consisted of 252 liver transplantations: 252 donors and 240 recipients (12 re-transplantations). Of the recipients, there were 179 (71.03\%) males and 73 (28.97\%) females. The mean age was $54.25 \pm 11.78$ years, hepatopathy etiology was alcoholic in 33.3\% ( $\mathrm{n}=75)$, hepatitis B and C in $17.34 \%(\mathrm{n}=39)$, and hepatocarcinoma in $12 \%(\mathrm{n}=27)$. The average MELD score was $21.17 \pm 8.06$, and considering the exception points it was $23.78 \pm 7.77$ (Table 1).

Table 1. Baseline characteristics of donors and recipients.

\begin{tabular}{l|c}
\hline Recipients $(\mathrm{n})$ & 240 \\
\hline Male gender \% (n) & $71.03(179)$ \\
\hline Age & $54.25 \pm 11.78$ \\
\hline White race \% (n) & $66.22(149)$ \\
\hline Body mass index (n) & $27.05 \pm 5.35$ \\
\hline Disease (alcohol-related) \% (n) & $33.3(75)$ \\
\hline MELD score & $21.17 \pm 8.06$ \\
\hline MELD score (adjusted) & $23.78 \pm 7.77$ \\
\hline MELD exception points \% (n) & $16.39(39)$ \\
\hline Re-transplantation & $4.76(12)$ \\
\hline Portal vein thrombosis & $6.34(16)$ \\
\hline Donors (n) & 252 \\
\hline Age & $41.47 \pm 15.82$ \\
\hline Black race \% (n) & $6.34(16)$ \\
\hline Height (centimeters) & $170 \pm 10.49$ \\
\hline Cause of death-cerebrovascular & $46.42(117)$ \\
\hline Donation site-regional & $91.67(231)$ \\
\hline Cold ischemia time (min) & $346 \pm 116.84$ \\
\hline
\end{tabular}

MELD: model for end stage liver disease. 
Organ donation occurred within the state of Paraná in $91.67 \%$ of cases $(n=231)$, donor's mean age was $41.47 \pm 15.82$ years, black race was observed in $6.34 \%(n=16)$, and cerebrovascular etiology was the main cause of death in $46.42 \%$ $(\mathrm{n}=117)$, as shown in Table 1 .

The cohort characteristics stratified according to the 30-day surgical mortality are shown in Table 2. DRI was the only prognostic variable without the statistical significance related to patients' 30-day surgical mortality.

The DMELD score ${ }^{3} 1600$ was observed in $3.98 \%(n=10)$ of transplants. The 30-day mortality in this group was $60 \%$. The surgical mortality was lower $(18.26 \%)$ on patients with the DMELD score $<1600$ ( $\mathrm{p}=0.0044)$.

The sensitivity, specificity, Youden's index, and AUROC were calculated for the indexes that showed differences between groups. MELD and DMELD showed AUC $<0.7$ (0.68 and 0.66, respectively). Therefore, these indexes were not associated with the 30-day mortality and were not used.

The ROC curve and AUC referred to BAR (0.7297), PSOFT (0.7717), and SOFT (0.7875) are shown on Figure 1.

The calculated Youden's index point was located within 11-12 score band for $\operatorname{BAR}(0.2484)$, 9-12 score band for PSOFT (0.3564), and 9-12 for SOFT (0.3453).

The 30-day survival for the group of transplants with scores up to $12(\mathrm{n}=172)$ in all these three indexes was $87.79 \%$, and for transplants with all the three indexes with scores higher than 12 it was $36.36 \%(\mathrm{p}=0.000)$. Considering simply one index, these results were 84.51 and $53.85 \%$ for BAR ( $\mathrm{p}=0.000$ ), 87.23 and $57.81 \%$ for SOFT $(\mathrm{p}=0.000)$, and 86.67 and $45.24 \%$ for PSOFT $(\mathrm{p}=0.000)$, respectively.

\section{DISCUSSION}

The 30-day survival curve analysis showed the impact of several factors from the donor-recipient binomial. Currently, the MELD score is the criteria adopted for organ allocation ${ }^{11}$. It is a question of ethical debate whether the procedure should be indicated to patients with poorer prognosis ${ }^{12,13}$.

The use of MELD improved organ allocation ${ }^{14}$; however, it does not have the same accuracy to predict the post-transplant mortality ${ }^{15}$. Thus, the post-transplantation MELD stratified survival analysis based on the international data would not be the representative of our reality. In our local cohort, the MELD score also did not show good sensibility and sensitivity to predict survival. Stratifying risk with more validated criteria in a local context is important to improve survival.

In our study, we observed the 30-day survival of $79.76 \%$. Improvement in transplant survival has led to an increased demand for organs. One of the solutions is the use of expanded criteria donors. Nowadays, it has become an essential part of the therapeutic strategy ${ }^{16}$. The donor risk assessment has already been validated on the literature. DRI is based on a study of 20,023 patients, and it considers several risk factors of donors 5 . In our series, neither split liver transplantation nor donor after cardiac death was observed. This eliminates the two main factors that influence the prognostic value of DRI ${ }^{17}$. Probably, this is the reason why there was no DRI difference related to mortality and survival. Another explanation is that expanded criteria organs are uniformly used in the state. This is corroborated by the findings of another local study with a cohort from a period immediately prior to the present study ${ }^{17}$, although our mean DRI is lower than the reported on other Brazilian regions ${ }^{18}$, a value observed in our third quartile.

Table 2. Risk indexes according to the 30-day mortality.

\begin{tabular}{l|c|c|c|c}
\multirow{2}{*}{} & \multirow{2}{*}{$\begin{array}{c}\text { Cohort } \\
(\mathrm{n}=252) \\
\%\end{array}$} & \multicolumn{2}{|c}{ 30-day mortality } \\
\cline { 2 - 5 } & $21.17 \pm 8.06$ & $\begin{array}{c}\text { Yes }(\mathrm{n}=51) \\
20.24\end{array}$ & $\begin{array}{c}\text { No }(\mathrm{n}=201) \\
79.76\end{array}$ \\
\hline MELD & $23.78 \pm 7.77$ & $24.92 \pm 9.09$ & $20.21 \pm 7.51$ & $0.0013^{*}$ \\
\hline MELDa & $1.44 \pm 0.35$ & $27 \pm 11.01$ & $22.96 \pm 6.48$ & $0.0157 *$ \\
\hline DRI & $849.08 \pm 397.30$ & $1.48 \pm 0.38$ & $1.43 \pm 0.34$ & 0.5341 \\
\hline DMELD & $8.21 \pm 4.31$ & $1015.94 \pm 470.23$ & $806.74 \pm 365.95$ & $0.057 *$ \\
\hline BAR & $8.87 \pm 6.93$ & $10.60 \pm 5.28$ & $7.61 \pm 3.81$ & $0.001 *$ \\
\hline PSOFT & $9.14 \pm 7.12$ & $13.80 \pm 9.87$ & $7.62 \pm 5.31$ & $0.0001 *$ \\
\hline SOFT & $14.07 \pm 9.67$ & $7.89 \pm 5.70$ & $0.0000^{*}$ \\
\hline
\end{tabular}

MELD: model for end stage liver disease; MELDa: MELD-adjusted; DRI: donor risk index; DMELD: donor model for end stage liver disease; BAR: balance of risk; PSOFT: Preallocation survival outcomes following liver transplant; SOFT: survival outcomes following liver transplant. * $\mathrm{p}<0.05$. 


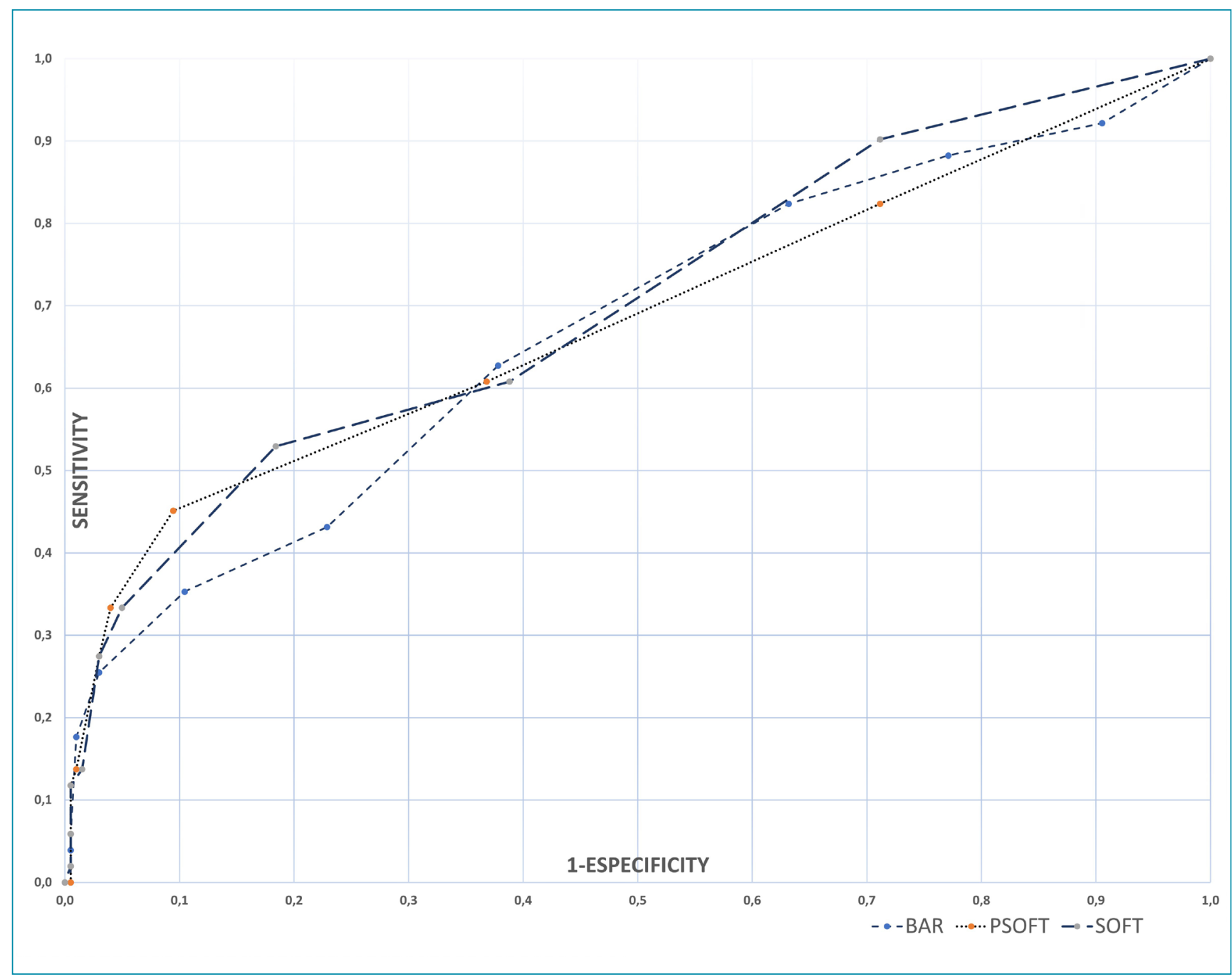

Figure 1. Receiver operating characteristic curve for balance of risk, preallocation and survival outcomes following liver transplant prognostic indexes.

Donor's age is an important risk factor for DRI. It influences two other components of the index ${ }^{5}$, namely, etiology of brain death and cold ischemia time. Hence, another index was proposed to aid the allocation decision process ${ }^{19}$. DMELD is an index obtained by the multiplication of donor age and recipient's MELD score. Groups with DMELD $>1600$ (i.e., $9.2 \%$ of the sample from the seminal study) had less than 1-year survival rate ${ }^{8}$. In our cohort, the group with DMELD $\geq 1600$ presented much higher surgical mortality (60\%). Nevertheless, DMELD, as occurred to MELD, did not show good sensitivity and sensibility to predict survival (i.e., $A U C=0.66$ ), corroborating the findings of another Brazilian cohor $\mathrm{t}^{20}$.

Risk models that predict the post-transplant mortality aggregating donor and recipient characteristics, such as $\mathrm{SOFT}^{7}$ and $\mathrm{BAR}^{6}$ scores, are shown to be good prognostic models.
These scores, despite considering cold ischemia time, can be calculated at the time of an organ offer.

In our study, BAR score performed well, predicting the surgical mortality after liver transplant. The BAR score was formulated based on 37,255 patients of USA and Switzerland ${ }^{6}$. In another Brazilian cohort, BAR score demonstrated suboptimal performance ${ }^{18}$. In the original study, deterioration in survival was observed after 18 points as a cutoff value ${ }^{6}$. In the Brazilian context, the cutoff value was estimated at 11 points ${ }^{18}$, in agreement with our findings, where the cutoff value was located in the range of 11-12.

We did not identify previous studies evaluating PSOFT and SOFT scores in the Brazilian population. Both presented better prognostic value than BAR used in our study. The cutoff value for both PSOFT and SOFT scores was in the stratification range of 9-12. Based on 21,673 North American patients ${ }^{7}$, 
PSOFT and SOFT scores include the anatomical characteristics (i.e., portal vein thrombosis and previous abdominal surgery) not included in BAR score. As with BAR score, the original PSOFT and SOFT study showed higher cutoff value for worse prognosis (36 points) than our findings.

Why is that? We can assume that in more developed countries more critical patients had better survival. It could be related to donor maintenance, organ harvesting solutions, dedicated anesthesiology, and ICU teams, medical supplies, etc. Although the 30-day mortality is acceptable for a developing country, our study shows that this rate may be improved.

When we aggregated the maximum cutoff values of the best performance scores in our analysis (i.e., BAR, SOFT, and PSOFT), we observed a survival rate of only $36.6 \%$. This is a very relevant data, although it is a clinical and ethical challenge to deny a liver transplant based on risk analysis.

\section{CONCLUSIONS}

(A) The 30-day liver transplantation survival of $79.76 \%$ observed in our state is acceptable and comparable with other Brazilian services.

(B) BAR, SOFT, and PSOFT are the validated post-transplant survival prognostic scores in our state.

(C) The cutoff value of 12 points is able to identify enhanced risk situations.

\section{AUTHORS" CONTRIBUTION}

FS: Conceptualization, Data curation, Formal Analysis, Writing - original draft, Writing - review \& editing. FPS: Data curation, Formal Analysis. ACTF: Conceptualization, Data curation, Formal Analysis, Writing - original draft, Writing - review \& editing. JCUC: Writing - review \& editing. EJBR: Data curation. MMM: Data curation. NT: Data curation. LCB: Data curation.

\section{REFERENCES}

1. Busuttil RW, Klintmalm G. Transplantation of the liver. 3th ed. Texas: Elsevier Saunders; 2015. 1568 p.

2. Dindo D, Demartines N, Clavien PA. Classification of surgical complications: a new proposal with evaluation in a cohort of 6336 patients and results of a survey. Ann Surg. 2004;240(2):205-13. https://doi.org/10.1097/01. sla.0000133083.54934.ae

3. Feng S, Goodrich NP, Bragg-Gresham JL, Dykstra DM, Punch JD, DebRoy MA, et al. Characteristics associated with liver graft failure: the concept of a donor risk index. Am J Transplant. 2006;6(4):783-90. https://doi.org/10.1111/j.16006143.2006.01242.x

4. Dutkowski P, Oberkofler CE, Slankamenac K, Puhan MA, Schadde E, Mullhaupt B, et al. Are there better guidelines for allocation in liver transplantation? A novel score targeting justice and utility in the model for end-stage liver disease era. Ann Surg. 2011;254(5):745-53; discussion 753. https://doi. org/10.1097/SLA.0b013e3182365081

5. Rana A, Hardy MA, Halazun KJ, Woodland DC, Ratner $L E$, Samstein B, et al. Survival outcomes following liver transplantation (SOFT) score: a novel method to predict patient survival following liver transplantation. Am J Transplant. 2008;8(12):2537-46. https://doi.org/10.1111/j.16006143.2008.02400.x

6. Halldorson JB, Bakthavatsalam R, Fix O, Reyes JD, Perkins JD. D-MELD, a simple predictor of post liver transplant mortality for optimization of donor/recipient matching. Am J Transplant. 2009;9(2):318-26. https://doi.org/10.1111/j.16006143.2008.02491.x

7. Associação Brasileira de Transplante de Órgãos. Registro Brasileiro de Transplantes [internet].São Paulo: ABTO; 2019. [cited on Dec. 20, 2020]. Available from: https://site.abto. org.br/publicacao/rbt-2019

8. Diretrizes do Sistema Estadual de Transplantes do Paraná. Central Estadual de Transplantes do Paraná; 2012.
9. Silveira CRS, Silveira F, Silveira FP, Saucedo Júnior N. Complicações nos primeiros 30 dias pós-transplante hepático - instrumento para avaliação no âmbito do sistema estadual de transplantes do Paraná. JBT J Bras Transpl. 2018 [cited on Dec. 20, 2020];20(2):1-76. Available from: https://site.abto. org.br/wp-content/uploads/2020/06/JBT-2018-2-1.pdf

10. Dean AG, Arner TG, Sunki GG, Friedman R, Lantinga M, Sangam $S$, et al. Epi Info'T, a database and statistics program for public health professionals. Atlanta: CDC. 2011 [cited on Dec. 21, 2020]. Available from: https://www.cdc.gov/epiinfo/index.html

11. Asrani SK, Kim WR. Model for end-stage liver disease: end of the first decade. Clin Liver Dis. 2011;15(4):685-98. https:// doi.org/10.1016/j.cld.2011.08.009

12. Linecker $M$, Krones $T$, Berg $T$, Niemann $C U$, Steadman $R H$, Dutkowski $\mathrm{P}$, et al. Potentially inappropriate liver transplantation in the era of the "sickest first" policy - a search for the upper limits. J Hepatol. 2018;68(4):798-813. https://doi.org/10.1016/j. jhep.2017.11.008

13. Keller EJ, Kwo PY, Helft PR. Ethical considerations surrounding survival benefit-based liver allocation. Liver Transpl. 2014;20(2):140-6. https://doi.org/10.1002/lt.23780

14. Wiesner $\mathrm{RH}$. Evolving trends in liver transplantation: listing and liver donor allocation. Clin Liver Dis. 2014;18(3):519-27. https://doi.org/10.1016/j.cld.2014.05.014

15. Desai NM, Mange KC, Crawford MD, Abt PL, Frank AM, Markmann JW, et al. Predicting outcome after liver transplantation: utility of the model for end-stage liver disease and a newly derived discrimination function. Transplantation. 2004;77(1):99-106. https://doi.org/10.1097/01. TP.0000101009.91516.FC

16. Silveira F, Silveira FP, Macri MM, Nicoluzzi JE. Análise da mortalidade na lista de espera de fígado no Paraná, Brasil o que devemos fazer para enfrentar a escassez de órgãos? Arq Bras Cir Dig. 2012;25(2):110-3. https://doi.org/10.1590/ s0102-67202012000200010 
17. Freitas ACT, Coelho JCU, Watanabe MR, Lima RLDC. Relationship between donor quality and recipient gravity in liver transplant. Arq Bras Cir Dig. 2020;33(1):e1499. https:// doi.org/10.1590/0102-672020190001e1499

18. Campos Junior ID, Stucchi RS, Udo EY, Boin Ide F. Application of the BAR score as a predictor of short- and long-term survival in liver transplantation patients. Hepatol Int. 2015;9(1):113-9. https://doi.org/10.1007/s12072-0149563-3
19. Avolio AW, Halldorson JB, Lirosi MC, Lupo L, Nicolotti N, Agnes S. D-MELD, a strong and accurate tool to guide donor2-recipient matching. Ann Transplant. 2013;18:161-2. https:// doi.org/10.12659/AOT.883876

20. Costabeber AM, Lionço LC, Marroni C, Zanotelli ML, Cantisani G, Brandão A. D-MELD does not predict post-liver transplantation survival: a single-center experience from Brazil. Ann Hepatol. 2014;13(6):781-7. https://doi.org/10.1016/ S1665-2681(19)30980-9 